\title{
Research on Dynamic Game Model and Application of China's Imported Soybean Price in the Context of China-US Economic and Trade Friction
}

\author{
Yi Wang $\mathbb{D}^{1},{ }^{1}$ Hui Wang, ${ }^{1}$ and Shubing Guo $\mathbb{D}^{2}$ \\ ${ }^{1}$ Shandong University of Finance and Economics, School of Mathematics and Quantitative Economics, Jinan 250014, China \\ ${ }^{2}$ College of Management and Economics, Tianjin University, Tianjin 300072, China
}

Correspondence should be addressed to Yi Wang; ywangsd2015@126.com and Shubing Guo; sbguo20160831@126.com

Received 1 June 2019; Accepted 9 September 2019; Published 12 November 2019

Guest Editor: Francisco G. Montoya

Copyright (C) 2019 Yi Wang et al. This is an open access article distributed under the Creative Commons Attribution License, which permits unrestricted use, distribution, and reproduction in any medium, provided the original work is properly cited.

China's soybean price fluctuates due to the current economic and trade frictions between China and the United States. Brazil and the United States are regarded as two oligarchs in China's soybean import market. A dynamic price game model is established, and price elasticity parameters are estimated by using statistical data and Rotterdam model. The stability of Nash equilibrium point is discussed through bifurcation diagram, maximum Lyapunov exponent, evolutionary trajectory, and time series diagram. The influence of price adjustment speed on equilibrium price is analyzed. The numerical simulation of price adjustment speed is carried out, which is compared with the actual situation of imported soybean price before and after the trade friction. The results show that the model constructed in this paper can reflect the changing trend of price and demand and predict the short-term import soybean prices of Brazil and the United States. The forecast accuracy of price fluctuation is high. The results provide model and theoretical reference for price game under trade disputes and provide methodological reference for forecasting the price of imported goods.

\section{Introduction}

Soybean is an important food crop in China. With the rapid development of economy and society, China's demand for soybeans is increasing year by year. Due to the limitation of domestic planting area and huge demand for soybeans, China's soybean production is far from self-sufficient, and imported soybeans have become the main source of demand for soybeans in China. Today, China is the world's largest soybean importer, accounting for $62.6 \%$ of global soybean exports. Brazil, the United States, and Argentina are the main sources of China's soybean imports, accounting for more than $95 \%$ of China's total soybean imports. Brazil and the United States account for more than $70 \%$ of China's soybean imports, and in recent years, their share has even exceeded $80 \%$. Brazil and the United States become the two oligarchy source countries of China's soybean import market.
Since July 6, 2018, China has imposed a $25 \%$ tariff on US soybeans. China's demand for US soybeans has declined, and as a buyer of soybeans, China has turned its attention to other countries. However, some Brazilian soybean farmers raised their prices by as much as $8 \%$ in a month. Argentina suffered from drought and soybean production plummeted. China's soybean production is insufficient, and the huge demand for soybeans for domestic life and production makes the price of imported soybeans fluctuate. Therefore, it is of great practical significance to study and compare the changes of soybean price before and after the trade friction.

The application of game theory and complexity theory to product market has always been a hot topic for international scholars. A lot of research is to analyze the complexity of market hypothesis as oligopoly market. Limited rationality and incomplete information are embodied in parameters that cannot be fixed in the model. Once the parameters of describing the economic system change across the linear 
stable region, they may change qualitatively, resulting in seemingly complex multiperiodic and nonperiodic motions. In the aspect of complexity analysis of oligopoly model, Agiza et al. [1-4] studied the dynamic behavior of the limited rational yield adjustment model and found stable period, quasi-periodic bifurcation, and chaos phenomena. Considering the influence of incomplete information, bounded rationality, and other factors on enterprises, they give the equilibrium output solution of the dynamic model. Bischi and Lamantia [5] proposed a Cournot duopoly monopoly game. Considering the interdependence between enterprises under given demand function, cost reduction simulation technology spillover is introduced.

In order to study whether oligarchy types affect Nash equilibrium, Tramontana [6] studied the duopoly competition of bounded rationality and naive type. On the premise of equal elastic demand function, they analyzed the evolution of Neimark-Sacker bifurcation and Flip bifurcation to chaos, respectively, and proved that the type of oligarch did not affect Nash equilibrium, but affected its stability, as well as the chaotic state entered after instability. Bonatti et al. [7] considered that, in a signaling oligopoly, market prices are impacted by unobservable demand. In a long enough time range, the game converges to the static result of complete information.

For the Cournot or duopoly models, Nagurney and Wolf [8] developed a game theory model of a service-oriented Internet in which profit-maximizing service providers provide substitutable services and compete with the quantities of services in a Cournot-Nash manner. Matouk et al. [9] established a nonlinear Quadropoly game based on Cournot model with fully heterogeneous players. Wang et al. [10] developed an integrated duopoly model for coordinating $\mathrm{R} \& \mathrm{D}$, product positioning, and pricing strategy. Taking the product substitutability into account, Nie [11] considered the horizontal mergers under Cournot with Bertrand competition. Saglam [12] provided a welfare ranking for the equilibria of the supply function and quantity competitions in a differentiated product duopoly with demand uncertainty. A dynamic Cournot game characterized by players with bounded rationality is modeled by two nonlinear difference equations in [13]. Wang and $\mathrm{Ma}$ [14] considered a Cournot-Bertrand mixed duopoly model with different expectations, where the market has linear demand and the firms have fixed marginal cost functions. In this article, we will apply a Cournot model to the trade friction problem, study the nature of the model through modeling and dynamics analysis, and explain the trade friction phenomenon.

For game model and dynamics analysis, a lot of work has been done in research of the supply chains. Guo and Ma [15] applied the theory of nonlinear dynamic system to the cooperative advertising model in supply chain, modeled the decision-making mechanism of enterprises as a dynamic adjustment process, and analyzed the influence of key parameters on the stability of forward Nash equilibrium. Apart from bounded rationality, oligarchy types are characterized by diversification. Ma and Wang [16] discussed a dualchannel supply chain composed of one manufacturer and one retailer. For more research about supply chains, see [17-21].
For the study of dynamic games, evolutionary games are also very popular. Li et al. [22] presented a model of changing the intensity of interaction based on the individual behavior to study the iterated prisoner's dilemma game in social networks. In [23], results illuminated the conditions under which the steady coexistence of competing strategies is possible. These findings revealed that the evolutionary fate of the coexisting strategies can be calculated analytically and provided novel hints for the resolution of cooperative dilemmas in a competitive context. For more research about evolutionary game theory, see $[24,25]$.

For the research about the application of game theory in economics and management, see [26-31]. Ma and Guo [26] considered dynamic game with estimation and two-stage consideration. The results have an important theoretical and practical significance to the game models with two-stage consideration. $\mathrm{Ma}$ and $\mathrm{Wu}$ [27] applied heterogeneous Triopoly game with multiproduct to related markets. In [28], macroeconomic model with time delays is discussed. Recently, in [29], Ma et al. established a cold chain dynamic game model including a milk manufacturer and two downstream oligopoly supermarkets under the wholesale price contract in the real world. Mu et al. [30] proposed a real estate game model with nonlinear demand function. And an analysis of the game's local stability was carried out. It was shown that the stability of Nash equilibrium point is lost through period-doubling bifurcation as some parameters are varied. The authors discussed a nonlinear four oligopolies price game with heterogeneous players using two different special demand costs in [31]. Based on the theory of complex discrete dynamical system, the stability and the existing equilibrium point are investigated.

However, these models focus on abstract and parameter discussion, but not on the reality of models. In this paper, we will not only model and perform dynamic analysis but also estimate the parameters in the model through statistical and quantitative methods. Furthermore, we will try to predict future prices by the game model.

On the methods of calculation and analysis, Wang et al. [32] took needs as the starting point, used the trade-off model between accuracy and information quantity as the optimization criterion to construct the confidence interval, derived the theoretical formula of the optimal confidence interval, and proposed a practical and efficient algorithm based on entropy theory and complexity theory. The accurate positioning of market oligarchs directly affects the accuracy and practical value of stability analysis of game models.

On the game model of agricultural products, with the innovation of industrial model, based on evolutionary game theory, Su et al. $[33,34]$ established the income matrix and replication dynamic equation of the tripartite game and discussed and analyzed the effectiveness, stability, and key factors of the new industrial model of agricultural supermarket docking. They used multivariate test to identify the nonlinearity, fractal, and chaos of the data. It is found that there is some confusion in the wholesale price data of agricultural products in China.

At present, there are few studies on dynamic analysis of agricultural product price game model by Chinese scholars. 
In this paper, the soybean import market in China is assumed to be a duopoly market, and a bounded rational duopoly dynamic price game model is established. Using game theory and chaotic dynamics theory, the import price of soybean from Brazil and the United States was analyzed dynamically.

This paper studies the stability of equilibrium point, discusses the impact of price adjustment speed of oligarchy countries on the stable region, simulates the price evolution law by using data statistics, and predicts the future soybean import price and its trend. The innovation of this paper is to use Rotterdam model and statistical data to estimate the actual elasticity coefficient and specific price adjustment speed value, to realize the abstract dynamic model, and to get the actual equilibrium price. It provides theoretical basis and price forecasting methods for predicting the trend of soybean import price under trade disputes and formulating soybean import strategy [33-39].

\section{Price Game Model}

China's soybean imports mainly come from the United States, Brazil, and Argentina, the three largest soybean producers in the world. According to the statistics of soybean imports from China's Customs and the Ministry of Agriculture and Rural Areas, Table 1 lists the proportion of soybean imports from the United States and Brazil in China from 2006 to 2017. Since 2011, soybeans from the United States and Brazil have accounted for more than $80 \%$ of the country's soybean imports. In this section, Brazil and the United States are regarded as the two oligarchs in China's soybean import market. Based on duopoly game model, a dynamically adjusted duopoly game model is established.

2.1. Model Assumptions. In order to get a reasonable conclusion, this paper simplifies the complex game process and makes the following assumptions in line with the laws of economy and trade.

Hypothesis 1. Brazil and the United States as two oligarchs for China's soybean imports, in order to make a more intuitive dynamic analysis of the game model, it is assumed that the imported soybeans from Brazil and the United States are of the same kind, and the price of soybeans is the average import price after paying taxes.

Hypothesis 2. According to the statistics of Wind Financial Terminal, the import costs of soybeans from South America and the United States are mainly inland freight, sea freight, port miscellaneous and insurance costs. In a year, sometimes the cost will be very close, and sometimes there will be a 100 yuan/ton gap, accounting for about $2.5 \%$ of the import price per ton. Therefore, this paper ignores the difference of arrival cost between Brazilian and American soybean imports. Assuming that the import costs of Brazilian and American soybeans are the same, the symbol $w$ is used.
TABle 1: China's share of soybean imports from Brazil and the United States in 2006-2017.

\begin{tabular}{lccc}
\hline Time & Brazil (\%) & America (\%) & The sum (\%) \\
\hline 2006 & 41.19 & 34.95 & 76.14 \\
2007 & 34.34 & 37.75 & 72.09 \\
2008 & 31.13 & 41.22 & 72.35 \\
2009 & 37.59 & 51.25 & 88.84 \\
2010 & 33.93 & 43.06 & 76.99 \\
2011 & 39.18 & 42.47 & 81.65 \\
2012 & 40.92 & 44.48 & 85.4 \\
2013 & 50.17 & 35.12 & 85.29 \\
2014 & 44.82 & 42.06 & 86.88 \\
2015 & 49.09 & 34.76 & 83.85 \\
2016 & 45.68 & 40.42 & 86.1 \\
2017 & 54.41 & 34.19 & 88.6 \\
\hline
\end{tabular}

Hypothesis 3. Under the bounded rationality, the game of soybean sales between the two countries is set as a duopoly game model. The two sides of the game take price adjustment as a game strategy to maximize their own interests. They make decisions independently at discrete periodic points $t=0,1,2 \ldots$.

Hypothesis 4. Assume that the demand function $q_{i}(i=1,2)$ is

$$
\begin{aligned}
& q_{1}=a_{1}-b_{1} p_{1}+c_{1} p_{2}, \\
& q_{2}=a_{2}-b_{2} p_{2}+c_{2} p_{1},
\end{aligned}
$$

where $p_{1}$ indicates the price of soybeans imported from Brazil by China, $p_{2}$ indicates the price of soybeans imported from the United States, $q_{1}$ indicates China's demand for Brazilian soybeans, $q_{2}$ indicates China's demand for American soybeans, $a_{1}$ indicates China's demand preference for Brazilian soybeans, and $a_{2}$ indicates China's demand preference for American soybeans. $-b_{1}$ shows the effect of the rising price of imported Brazilian soybean on the demand of imported Brazilian soybean in China. It is the marginal demand of imported Brazilian soybean. $-b_{2}$ shows the effect of the rising price of imported American soybean on the demand of imported American soybean in China. It is the marginal demand of imported American soybean. The symbol $c_{1}$ is used to represent the impact of the rising price of imported US soybeans on China's demand for imported Brazilian soybeans, $c_{2}$ is used to indicate the impact of the rising price of imported Brazilian soybeans on China's demand for imported US soybeans.

Hypothesis 5. As the number of soybeans imported by China from Brazil and the United States is increasing year by year, before the trade friction, China had a positive demand preference for soybeans imported from Brazil and the United States. After the outbreak of the trade friction, China's demand preference for imported soybeans from Brazil remained positive, while other countries except Brazil could not fill the gap of imported soybeans from the United States in the short term. Therefore, in the short run, China 
still has a positive demand preference for imported soybeans from the United States. So we assume $a_{1}>0, a_{2}>0$.

Hypothesis 6. In the commodity market, people's demand for a certain commodity is affected by the commodity's own price and the price of similar substitutes. The rise of the product's own price will lead to the decrease in the demand for the product, and the rise of the price of similar substitutes will increase people's consumption of the commodity. So we assume $b_{1}>0, b_{2}>0, c_{1}>0, c_{2}>0$.

Hypothesis 7. Assuming that the participants in the competition are bounded rationality, the two oligarchs constantly adjust their price strategies to carry out long-term repeated dynamic game. Suppose that the decision-making of the $t+1$ period is adjusted on the basis of the marginal income of the $t$ period and the repeated game model which satisfies the dynamic adjustment [13]. Suppose that the price of oligopoly $i(i=1,2)$ in $t+1$ is

$$
p_{i}(t+1)=p_{i}(t)+g_{i} \times p_{i}(t) \times \frac{\partial \pi_{i}(t)}{\partial p_{i}(t)},
$$

$g_{i} \geq 0$ denotes the rate of price adjustment of manufacturer $i(i=1,2)$.

2.2. Dynamic Adjustment of the Repeated Game Model. Under the assumption in the previous section, the profit function $\pi_{i}(i=1,2)$ of two soybean manufacturers can be expressed as follows:

$$
\begin{aligned}
& \pi_{1}=q_{1}\left(p_{1}-w\right)=\left(a_{1}-b_{1} p_{1}+c_{1} p_{2}\right)\left(p_{1}-w\right), \\
& \pi_{2}=q_{2}\left(p_{2}-w\right)=\left(a_{2}-b_{2} p_{2}+c_{2} p_{1}\right)\left(p_{2}-w\right) .
\end{aligned}
$$

Marginal profit is

$$
\begin{aligned}
& \frac{\partial \pi_{1}}{\partial p_{1}}=a_{1}-2 b_{1} p_{1}+c_{1} p_{2}+b_{1} w, \\
& \frac{\partial \pi_{2}}{\partial p_{2}}=a_{2}-2 b_{2} p_{2}+c_{2} p_{1}+b_{2} w .
\end{aligned}
$$

If the marginal profit is equal to 0 , the Cournot-Nash equilibrium price is

$$
\begin{aligned}
& p_{1}=\frac{a_{1} b_{2}-a_{2} b_{1}+2 b_{1} b_{2} p_{2}+b_{2} c_{1} p_{2}}{b_{1}\left(2 b_{2}+c_{2}\right)}, \\
& p_{2}=\frac{-2 a_{2} b_{1}-a_{1} c_{2}+4 b_{1} b_{2} p_{2}-c_{1} c_{2} p_{2}}{b_{1}\left(2 b_{2}+c_{2}\right)} .
\end{aligned}
$$

By introducing (3) into (2), the dynamic model of two oligopoly games is obtained:

$$
\begin{aligned}
& p_{1}(t+1)=p_{1}(t)+g_{1} \times p_{1}(t) \times a_{1}-2 b_{1} p_{1}(t)+c_{1} p_{2}(t)+b_{1} w, \\
& p_{2}(t+1)=p_{2}(t)+g_{2} \times p_{2}(t) \times\left(a_{2}-2 b_{2} p_{2}(t)+c_{2} p_{1}(t)+b_{2} w\right) .
\end{aligned}
$$

It can be seen from (6) that oligarchs will adjust their decision-making according to the current marginal profits in order to pursue profits. If margins are positive, they will raise prices in the next period and, vice versa, lower prices.

2.3. Parameter Estimation. In this section, based on the actual data obtained, the parameters in model (6) will be estimated by statistical methods, and more practical concrete model will be obtained. Since only the annual soybean demand samples from 2006 to 2017 can be obtained at present, this paper uses Rotterdam model suitable for small sample data to study China's soybean import demand. In order to make the study more accurate, the United States, Brazil, and Argentina, which account for more than 95\% of total imports, are brought into the Rotterdam model.

2.3.1. Rotterdam Model. The Rotterdam model was first proposed by Barten (1964) and Theil [35]. This model can reasonably estimate the expenditure elasticity and price elasticity of demand under the condition of unsatisfactory sample size. It is widely used in the research of agricultural import demand. The form of this model is as follows:

$$
\omega_{i} d \log q_{i}=r_{i}+\alpha_{i} d \log Q+\sum_{i, j=1}^{n} \beta_{i j} d \log p_{i},
$$

for $i, j=1,2,3$, where $\omega_{i}$ represents the proportion of China's imports of soybeans from country $i$ to the total imports of soybeans, $q_{i}$ represents China's soybean imports from countries $i, p_{i}$ represents the import price of soybeans from country $i, d \log q_{i}$ represents the incremental ratio of imported soybeans, $d \log p_{i}$ represents the increase ratio of import prices, $r_{i}$ represents the change of consumption demand of imported soybean caused by nonprice factors in the model, $\alpha_{i}$ is the Chinese marginal expenditure share on imported soybeans, and $\beta_{i j}$ represents the compensation price coefficient. When the model is applied, $\omega_{i}$ is usually approximated to $\left(\omega_{i}+\omega_{i-1}\right) / 2, d \log q_{i}$ is usually approximated to $\left(\omega_{i}+\omega_{i-1}\right) / 2$, $d \log p_{i}$ is usually approximated to $\log \left(p_{i} / p_{i-1}\right)$, and $d \log Q$ is usually approximated to $\sum_{i=1}^{n} \omega_{i} d \log q_{i}$.

At the same time, the Rotterdam model needs to satisfy the following restrictions: (1) adding-up $\sum_{i=1}^{n} \alpha_{i}=1, \sum_{i=1}^{n} \beta_{i j}=0$; (2) homogeneity $\sum_{j=1}^{n} \beta_{i j}=0$; (3) symmetry $\beta_{i j}=\beta_{j i}$.

2.3.2. Model Fitting. This paper collects the statistical data of China's soybean import trade from 2006 to 2017, mainly from China Customs, Ministry of Agriculture and Rural Areas, and Wind Financial Terminal. Some data are converted and sorted out. The integrated data are applied to this study. In order to make the dynamic analysis image more intuitive, the price dimension is selected as yuan/half kilogram. In the latter analysis, the price dimension will be converted into yuan $/ \mathrm{kg}$.

Firstly, the relevant data collected are converted into Rotterdam model by units, and $\alpha_{i}, \beta_{i j}(i, j=1,2,3)$ is fitted; then Slutsky price elasticity is used to derive price elasticity and cross-price elasticity [36].

Slutsky price elasticity is the price elasticity after eliminating the income effect, that is, the change of demand caused by the change of commodity price and the change of real 
income. We can get self-price elasticity by $\eta_{i i}=\beta_{i i} / \omega_{i}$ and get cross-price elasticity by $\eta_{i j}=\beta_{i j} / \omega_{i}$. Through model fitting, the constant term $r_{i}$, the marginal expenditure share of imported soybean $\alpha_{i}$, and the compensation price coefficient $\beta_{i j}$ can be obtained as shown in Table 2 . The price elasticity coefficient is calculated from the proportion of imports $\omega_{i}$ and the compensation price coefficient $\beta_{i j}$. According to the Cournot model, Table 3 lists the price elasticity calculated from the parameters in Table 2. We remark that the data in parentheses are the $t$-statistics of the corresponding parameter estimators; the symbols $*, * *$, and $* * *$ represent the levels of significance at $10 \%, 5 \%$, and $1 \%$, respectively.

As can be seen from Table 3, the self-price elasticity coefficients of soybeans in Argentina, Brazil, and the United States are $-3.2,-1.5$, and -1.6 , respectively. The price elasticities are negative, the cross-price elasticities between the main source countries are greater than 0 , and the demand variations caused by nonprice factors described by the constant term are also greater than 0 . They are in line with the actual economic significance.

Letting $-b_{1}=-1.5,-b_{2}=-1.6, c_{1}=1$, and $c_{2}=1.2$, the import quantities of soybeans from Brazil and the United States are weighted and the import demand parameters of Brazil and the United States are obtained as $a_{1}=2.3$ and $a_{2}=2.1$. According to the statistics, the cost $w$ after unit conversion fluctuates is approximately equal to 0.26 . Therefore, we get a concrete duopoly dynamic game model of soybean price:

$$
\begin{aligned}
& p_{1}(t+1)=p_{1}(t)+g_{1} \times p_{1}(t) \times\left(2.69-3 p_{1}(t)+p_{2}(t)\right), \\
& p_{2}(t+1)=p_{2}(t)+g_{2} \times p_{2}(t) \times\left(2.516-3.2 p_{2}(t)+1.2 p_{1}(t)\right) .
\end{aligned}
$$

\section{Equilibrium Point and Stability Analysis of Model}

In this section, by solving the equilibrium points of system (6), the stability of each equilibrium point is analyzed, and the condition that Nash equilibrium points satisfy the local stability is obtained. The stability of the equilibrium point is further verified by the estimated values of the economic parameters in this section, which provides a reference range of $g_{i}(i=1,2)$ for the dynamic analysis of the game model in the future.

When $p_{i}(t+1)=p_{i}(t)(i=1,2)$, the four equilibrium points of the discrete system (6) are obtained as follows:

$E_{1}(0,0)$,

$E_{2}\left(0, \frac{a_{2}+b_{2} w}{2 b_{2}}\right)$

$E_{3}\left(\frac{a_{1}+b_{1} w}{2 b_{1}}, 0\right)$

$E_{4}\left(\frac{b_{2}\left(2 a_{1}+c_{1} w+2 b_{1} w\right)+a_{2} c_{1}}{4 b_{1} b_{2}-c_{1} c_{2}}, \frac{2 b_{1}\left(b_{2} w+a_{2}\right)+c_{2}\left(b_{1} w+a_{1}\right)}{4 b_{1} b_{2}-c_{1} c_{2}}\right)$

According to $a_{1}>0, a_{2}>0, b_{1}>0, b_{2}>0, c_{1}>0, c_{2}>0$, and $w>0$, these four equilibrium points are all nonnegative

\begin{tabular}{|c|c|c|c|c|c|}
\hline \multirow{2}{*}{ Country } & & & \multicolumn{3}{|c|}{$\beta_{i j}$} \\
\hline & & & Argentina & Brazil & America \\
\hline Argentina & $\begin{array}{c}0.06 \\
(2.81)\end{array}$ & $\begin{array}{c}0.30^{*} \\
(0.435)\end{array}$ & $\begin{array}{c}-0.49 \\
(-0.011)\end{array}$ & $\begin{array}{l}0.31^{* *} \\
(2.98)\end{array}$ & $\begin{array}{l}0.19 \\
(1.2)\end{array}$ \\
\hline Brazil & $\begin{array}{c}0.35^{* * *} \\
(4.40)\end{array}$ & $\begin{array}{c}0.44^{* * *} \\
(4.40)\end{array}$ & & $\begin{array}{l}-0.61^{*} \\
(-1.10)\end{array}$ & $\begin{array}{l}0.38^{* *} \\
(3.82)\end{array}$ \\
\hline America & $\begin{array}{l}0.74^{* *} \\
(5.43) \\
\end{array}$ & $\begin{array}{c}0.26^{* * *} \\
(5.43) \\
\end{array}$ & & & $\begin{array}{c}-0.64^{* * *} \\
(-5.07) \\
\end{array}$ \\
\hline
\end{tabular}

TABLE 2: Estimation results of model parameters.

TABle 3: The price elasticity of China's demand for imported soybeans from different countries.

\begin{tabular}{lccc}
\hline Country & \multicolumn{3}{c}{ Price elasticity } \\
& Argentina & Brazil & America \\
\hline Argentina & -3.2 & 2.0 & 1.21 \\
Brazil & 0.7 & -1.5 & 1.0 \\
America & 0.5 & 1.2 & -1.6 \\
\hline
\end{tabular}

equilibrium solutions, and $E_{1}, E_{2}$, and $E_{3}$ are bounded equilibrium points and $E_{4}$ is a Nash equilibrium point. Next, we study the local stability of these four points.

Theorem 1. The bounded equilibrium points $E_{1}, E_{2}$, and $E_{3}$ are unstable points.

Proof. As we all know, (6) can be regarded as a dynamic system, and its Jacobian matrix is

$$
J=\left[\begin{array}{ll}
\frac{\partial p_{1}(t+1)}{\partial p_{1}(t)} & \frac{\partial p_{1}(t+1)}{\partial p_{2}(t)} \\
\frac{\partial p_{2}(t+1)}{\partial p_{1}(t)} & \frac{\partial p_{2}(t+1)}{\partial p_{2}(t)}
\end{array}\right],
$$

where

$$
\left\{\begin{array}{l}
\frac{\partial p_{1}(t+1)}{\partial p_{1}(t)}=1+g_{1}\left(a_{1}-2 b_{1} p_{1}+c_{1} p_{2}+b_{1} w\right)-2 b_{1} g_{1} p_{1}, \\
\frac{\partial p_{1}(t+1)}{\partial p_{2}(t)}=g_{1} p_{1} c_{1}, \\
\frac{\partial p_{2}(t+1)}{\partial p_{1}(t)}=g_{2} p_{2} c_{2}, \\
\frac{\partial p_{2}(t+1)}{\partial p_{2}(t)}=1+g_{2}\left(a_{2}-2 b_{2} p_{2}+c_{2} p_{1}+b_{2} w\right)-2 b_{2} g_{2} p_{2} .
\end{array}\right.
$$

At equilibrium point $E_{1}(0,0)$, the Jacobian matrix is

$$
J_{1}=\left[\begin{array}{cc}
1+g_{1}\left(a_{1}+b_{1} w\right) & 0 \\
0 & 1+g_{2}\left(a_{2}+b_{2} w\right)
\end{array}\right] .
$$


Two eigenvalues are $\lambda_{1}=1+g_{1}\left(a_{1}+b_{1} w\right)$ and $\lambda_{2}=1+$ $g_{2}\left(a_{2}+b_{2} w\right)$. Since $a_{i}>0, b_{i}>0(i=1,2), \lambda_{1}>1, \lambda_{2}>1$. So $E_{1}$ is unstable.

At equilibrium point $E_{2}\left(0,\left(a_{2}+b_{2} w / 2 b_{2}\right)\right)$, the Jacobian matrix is

$$
J_{2}=\left[\begin{array}{cc}
1+g_{1}\left(a_{1}+c_{1} \frac{a_{2}+b_{2} w}{2 b_{2}}+b_{1} w\right) & 0 \\
\frac{g_{2} c_{2}\left(a_{2}+b_{2} w\right)}{2 b_{2}} & 1-g_{2}\left(a_{2}+b_{2} w\right)
\end{array}\right]
$$

Two eigenvalues are $\lambda_{1}=1-g_{2}\left(a_{2}+b_{2} w\right)$ and $\lambda_{2}=1+$ $g_{1}\left(a_{1}+c_{1}\left(a_{2}+b_{2} w / 2 b_{2}\right)+b_{1} w\right)$. The feature vectors are $\gamma_{1}=(0,1)$ and

$$
\gamma_{2}=\left(\frac{b_{2} g_{1}\left(2 a_{1}+2 b_{1} w+c_{1} w\right)+b_{2} g_{2}\left(2 a_{2}+2 b_{2} w\right)+a_{2} c_{1} g_{1}}{c_{2} g_{2}\left(a_{2}+b_{2} w\right)}\right) .
$$

When $g_{2}<\left(2 / a_{2}+b_{2} w\right), E_{2}$ is a saddle point and is stable along the tangent of $\gamma_{1}$. When $g_{2}>\left(2 / a_{2}+b_{2} w\right), E_{2}$ is unstable. Since $E_{2}$ and $E_{3}$ have symmetrical structure, $E_{3}$ is also an unstable point. So $E_{1}, E_{2}$, and $E_{3}$ are unstable. This is the end of the proof.

Remark 1. (the economic parameters obtained in Section 2.4). $a_{1}=2.3, a_{2}=2.1, b_{1}=1.5, b_{2}=1.6, c_{1}=1, c_{2}=1.2$, and $w=0.26$ are put into the proof of theorem 1 . Then we obtained the three marginal equilibrium points $E_{1}(0,0)$, $E_{2}(0,(629 / 800))$, and $E_{3}((269 / 300), 0)$, respectively. The value of the three equilibrium points represents the corresponding value of the price of imported soybeans from the United States and Brazil in the context of the trade friction at that time.

Remark 2. The point $E_{1}(0,0)$ means that the price of imported soybeans from the United States and Brazil is 0, which means that there are no Brazilian and American soybeans sold in the commodity market, and China does not import soybeans from Brazil and the United States. If China were not importing soybeans from Brazil and the United States, there would be no imported soybeans from either country in circulation, and the equilibrium of zero prices would remain. However, the reality is that China still imports soybeans from Brazil and the United States from the past to the trade friction, so this balance does not exist in the reality.

Remark 3. The points $E_{2}(0,(629 / 800))$ and $E_{3}((269 / 300), 0)$ mean that the price of at least one imported soybean from the United States and Brazil is 0. Moreover, if the soybean price of either party becomes 0 , it will cause a rapid and substantial increase in the demand of the corresponding party, and the equilibrium will be broken quickly in a very short time, which is extremely unstable. According to the expression form before substituting into the parameter value, no matter what the value of price elasticity coefficient and price adjustment speed is, the equilibrium is unstable and cannot exist for a long time. From this point of view, the three equilibrium points $E_{1}, E_{2}$, and $E_{3}$ obtained by solving the discrete system (8) will not happen in the real economic situation. Even if it happens in a very small probability, the equilibrium will be spontaneously broken in a very short time under the action of the market. In such cases, there is no need for policy intervention to move towards generalization.

Next, we study the stability of point

$$
E_{4}\left(\frac{b_{2}\left(2 a_{1}+c_{1} w+2 b_{1} w\right)+a_{2} c_{1}}{4 b_{1} b_{2}-c_{1} c_{2}}, \frac{2 b_{1}\left(b_{2} w+a_{2}\right)+c_{2}\left(b_{1} w+a_{1}\right)}{4 b_{1} b_{2}-c_{1} c_{2}}\right) .
$$

Theorem 2. If $g_{1}, g_{2}$ satisfy

$$
\left\{\begin{array}{l}
1+j_{1}+j_{4}+j_{1} j_{4}-j_{2} j_{3}>0 \\
1-j_{1}-j_{4}+j_{1} j_{4}-j_{2} j_{3}>0 \\
\left|j_{1} j_{4}-j_{2} j_{3}\right|<1
\end{array}\right.
$$

then $E_{4}$ is stable, where

$$
\begin{aligned}
& j_{1}=1+g_{1}\left(\frac{a_{1}\left(1-c_{2}\right)+c_{1} c_{2}\left(2 a_{1}+2 b_{1} w\right)-2 b_{1} b_{2}\left(4 a_{1}+c_{1} w+4 b_{1} w\right)-b_{1} c_{2} w}{4 b_{1} b_{2}-c_{1} c_{2}}+b_{1} w\right) \\
& j_{2}=g_{1} c_{1} \frac{2 b_{1} b_{2}\left(2 a_{1}+c_{1} w+2 b_{1} w\right)-c_{1} c_{2}\left(a_{1}+b_{1} w\right)+c_{2}\left(b_{1} w+a_{1}\right)+2 a_{2} b_{1} c_{1}}{2 b_{1}\left(4 b_{1} b_{2}-c_{1} c_{2}\right)}, \\
& j_{3}=g_{2} c_{2} \frac{2 b_{1}\left(b_{2} w+a_{2}\right)+c_{2}\left(b_{1} w+a_{1}\right)}{4 b_{1} b_{2}-c_{1} c_{2}}, \\
& j_{4}=1+g_{2}\left(\frac{2 b_{1} b_{2}\left(6 a_{2}-4 b_{2} w+2 c_{2} w+2 a_{1} c_{2}+c_{1} c_{2} w\right)-c_{1} c_{2}\left(a_{2}+a_{1}+b_{1} w\right)}{4 b_{1} b_{2}-c_{1} c_{2}}+\frac{c_{2}\left(4 a_{1} b_{2}+3 b_{1} w+a_{1}\right)-2 a_{2} b_{1} c_{1}}{4 b_{1} b_{2}-c_{1} c_{2}}+b_{2} w\right) .
\end{aligned}
$$


Proof. The Jacobian matrix of $E_{4}$ is

$$
J_{4}=\left[\begin{array}{ll}
j_{1} & j_{2} \\
j_{3} & j_{4}
\end{array}\right] \text {. }
$$

The characteristic equation is

$$
f(\lambda)=\lambda^{2}-A \lambda+B \lambda=0,
$$

where

$$
\begin{aligned}
A= & \operatorname{tr}\left(J_{4}\right)=j_{1}+j_{4}, \\
B= & \operatorname{det}\left(J_{4}\right)=j_{1} j_{4}-j_{2} j_{3}, \\
\operatorname{tr} & \left(J_{4}\right)^{2}-4 \operatorname{det}\left(J_{4}\right)=\left(j_{1}+j_{4}\right)^{2}-4\left(j_{1} j_{4}-j_{2} j_{3}\right) \\
= & \left(j_{1}-j_{4}\right)^{2}+4 j_{2} j_{3} \\
= & \frac{F_{1}}{F_{2}}+\left(j_{1}-j_{4}\right)^{2}, \\
F_{1}= & 2 g_{1} g_{2} c_{1} c_{2} F_{11} F_{12}, \\
F_{2}= & b_{1}\left(4 b_{1} b_{2}-c_{1} c_{2}\right)^{2}, \\
F_{11}= & 2 b_{1} b_{2}\left(2 a_{1}+c_{1} w+2 b_{1} w\right)+2 a_{2} b_{1} c_{1} \\
& +c_{2}\left(b_{1} w+a_{1}\right)\left(1-c_{1}\right), \\
F_{12}= & 2 b_{1}\left(b_{2} w+a_{2}\right)+c_{2}\left(b_{1} w+a_{1}\right) .
\end{aligned}
$$

Since the values of parameters in economics are greater than 0 , we can obtain $\operatorname{tr}\left(J_{4}\right)^{2}-4 \operatorname{det}\left(J_{4}\right) \geq 0$. Thus, the Nash equilibrium point $E_{4}$ has real eigenvalues.

According to Jury condition [37], if $E_{4}$ is stable, it is necessary to satisfy

$$
\left\{\begin{array}{l}
1+\operatorname{tr}\left(J_{4}\right)+\operatorname{det}\left(J_{4}\right)>0, \\
1-\operatorname{tr}\left(J_{4}\right)+\operatorname{det}\left(J_{4}\right)>0, \\
\left|\operatorname{det}\left(J_{4}\right)\right|<1
\end{array}\right.
$$

When

$$
\left\{\begin{array}{l}
1+j_{1}+j_{4}+j_{1} j_{4}-j_{2} j_{3}>0 \\
1-j_{1}-j_{4}+j_{1} j_{4}-j_{2} j_{3}>0 \\
\left|j_{1} j_{4}-j_{2} j_{3}\right|<1
\end{array}\right.
$$

hold, $E_{4}$ is locally stable. By solving the inequality, the range of each parameter is obtained as follows:

$$
\begin{aligned}
& a_{1}>1.17, \\
& a_{2}>0.35, \\
& b_{1}>1.22, \\
& b_{2}>0.25, \\
& c_{1}>0.7, \\
& c_{2}>0.29, \\
& w>0.1 .
\end{aligned}
$$

This completes the proof.
We introduce the economic parameters $a_{1}=2.3, a_{2}=2.1$, $b_{1}=1.5, b_{2}=1.6$, and $c_{1}=1$ to the proofs of Theorem 2 . Then equilibrium point $E_{4}((927 / 700),(898 / 700))$ is obtained. For $E_{4}$, all the values of $a_{1}, a_{2}, b_{1}, b_{2}, c_{1}, c_{2}$ are within the range of (23). By using the values of estimated parameters, we can compute and get the Jacobian matrix:

$$
J_{4}=\left[\begin{array}{cc}
1-5.249 g_{1} & 1.3243 g_{1} \\
1.5394 g_{2} & 1+11.5186 g_{2}
\end{array}\right] \text {. }
$$

The characteristic equation is $f(\lambda)=\lambda^{2}-A \lambda+B \lambda=0$, where

$$
\begin{aligned}
& A=\operatorname{tr}\left(J_{4}\right)=2-5.249 g_{1}+11.5186 g_{2}, \\
& B=\operatorname{det}\left(J_{4}\right)=1+11.5186 g_{2}-5.249 g_{1}-62.5 g_{1} g_{2} .
\end{aligned}
$$

Since $\operatorname{tr}\left(J_{4}\right)^{2}-4 \operatorname{det}\left(J_{4}\right)=\left(5.249 g_{1}+11.5186 g_{2}\right)^{2}+$ $8.15451 g_{1} g_{2}, g_{1} \geq 0, g_{2} \geq 0$, and $\operatorname{tr}\left(J_{4}\right)^{2}-4 \operatorname{det}\left(J_{4}\right) \geq 0$, we can attain that $E_{4}((927 / 700),(898 / 700))$ has real eigenvalues.

According to the Jury condition,

$$
\left\{\begin{array}{l}
4-10.498 g_{1}+23.0372 g_{2}-62.5 g_{1} g_{2}>0, \\
11.5186 g_{2}-5.249 g_{1}-62.5 g_{1} g_{2}<0, \\
11.5186 g_{2}-5.249 g_{1}-62.5 g_{1} g_{2}>-2,
\end{array}\right.
$$

hold. The inequalities define the stable region of Nash equilibrium.

Remark 4. In the proof of Theorem 2, we calculate the stable level of $E_{4}$ under the condition of the value range of $g_{1}$ and $g_{2}$, that is, the analysis of local stability of $E_{4}$. That means that when the speed of price adjustment is controlled within a certain range, the price of imported American soybeans and Brazilian soybeans reaches the Nash equilibrium in the competition of product market. There is no fluctuation and the price of soybean market is stable. And when $g_{1}$ and $g_{2}$ go beyond a certain range, $E_{4}$ is no longer Nash equilibrium. Both prices adjust too fast, leading to a certain degree of fluctuations in the price of imported American soybeans and Brazilian soybeans. The equilibrium reached in the competition between the two will be broken, and the market price fluctuates, which is likely to have a certain impact on consumers' life and the healthy development of the product market. As for the reality, after the start of the trade friction, the imposition of high soybean tariffs will lead to the rapid rise of the price of imported soybeans in the United States, which will accelerate the speed of price adjustment in the model to some extent, and thus affect the equilibrium of soybean market.

In order to maintain the smooth operation of Chinese soybean market, China must take corresponding policies and measures according to the situation. When the speed of price adjustment increases slightly and the threat to soybean market equilibrium is relatively small, China should accelerate agricultural supply-side structural reform, appropriately increase soybean planting subsidies, encourage soybean planting, and increase research and development input. In this way, we can improve the quality and quantity 
of domestic soybeans in the future, reduce Chinese continuous dependence on imported soybeans, and increase domestic soybean supply. At the same time, we should increase the investment in soybean planting abroad, so as to effectively improve the enthusiasm of soybean planting in other countries, diversify the import market, and optimize the import choice. When the speed of price adjustment is greatly accelerated, which is a great threat to soybean market equilibrium, China can quickly turn the import channels to South America and southeast Asian countries in a short time and, at the same time, reduce the soybean import tariffs to these countries in the short term to make up for the US soybean import source gap. It is also possible to seek substitutes with similar nutrition and taste to soy products, reduce the price of substitutes, strengthen media publicity and popularization of nutrition knowledge, and stimulate people's enthusiasm for the consumption of substitutes.

\section{Simulation Analysis}

How does one know whether the equilibrium is affected according to the change of price adjustment speed, so as to know what kind of measures should be taken? Next, we will conduct simulation analysis on the speed of price adjustment and price change to make a more intuitive analysis.

In this section, the numerical dynamic evolution simulation of model (8) is carried out to observe the law of price evolution. The estimated values $a_{1}, a_{2}, b_{1}, b_{2}, c_{1}, c_{2}$ will remain relatively stable for a short time in the future. Therefore, after the trade friction, China's tax increase on imported soybeans from the United States is reflected in the rapid rise in the customs value of imported soybeans at a certain stage. Then the price fluctuates near the high level after rising, which is mainly reflected in the change of price adjustment speed $g$ in model (8). In this section, we study the effect of the change of the rate of price adjustment $g$ on the equilibrium price.

4.1. The Effect of Price Adjustment Speed on Equilibrium Price. From (2), we can reduce that

$$
g_{i}=\frac{p_{i}(t+1)-p_{i}(t)}{p_{i}(t)}\left(\frac{\partial \pi_{i}}{\partial p_{i}(t)}\right)^{-1} .
$$

According to the relevant data of imported Brazilian and American soybeans from 2006 to 2017 provided by Wind Financial Terminal, the price adjustment speeds of imported soybeans $g_{i}(i=1,2)$ from Brazil and the United States are calculated on the basis of (27). The values of $p_{i}(i=1,2)$ are taken as the average monthly prices of each year. The corresponding economic parameters obtained by Rotterdam model are introduced into $\left(\partial \pi_{i} / \partial p_{i}(t)\right)(i=1,2)$. According to the analysis based on accurate monthly data statistics, before the trade friction began, the adjustment speeds of imported soybean prices $g_{1}, g_{2}$ of Brazil and the United States changed slowly, fluctuating around 0.03 in the stable stage. Therefore, in this section, 0.03 is selected as the control value of speed adjustment.
Fixing the adjustment speed of imported US soybean price $g_{2}$, we can observe the changes of imported soybean prices of the two countries with the adjustment speed of imported Brazilian soybean price $g_{1}$. Assuming that the adjustment speed of imported US soybean price is $g_{2}=0.03$, with the change of the rate of price adjustment of imported Brazilian soybeans, the trajectories of $p_{1}$ and $p_{2}$ are shown in Figure 1 .

Fixing the adjustment speed of imported Brazilian soybean price $g_{1}$, we can observe the changes of imported soybean prices of the two countries with the adjustment speed of imported American soybean price $g_{2}$. Assuming that the adjustment speed of imported Brazilian soybean price is $g_{1}=0.03$, with the change of the US import soybean price adjustment speed $g_{2}$, the tracks of $p_{1}$ and $p_{2}$ are shown in Figure 2.

As can be seen from Figures 1 and 2, with the increase of the speed of price adjustment $g_{i}(i=1,2)$, soybean prices remain stable at the beginning, and oligarchs' profits are maximized. Neither side can make more profits by changing prices to reach Nash equilibrium $\left(p_{1}, p_{2}\right)=(1.324,1.283)$. However, too fast speed of price adjustment will break the state of stable equilibrium, and the system will enter the counter-periodic bifurcation. Faster price adjustment even leads to chaos in the system, resulting in disorder in the imported soybean market. Figure 3 shows the maximum Lyapunov exponents with $p_{1}$ and $p_{2}$ changing, respectively.

In the max Lyapunov exponent graph, when the max Lyapunov exponent equals 0 , the system bifurcates, and when the max Lyapunov exponent is greater than 0, the system enters chaos. The bifurcation and chaos in Figures 1 and 2 coincide with the change of largest Lyapunov exponent in Figure 3; that is, the system goes from stable state to double bifurcation and finally goes to chaos.

In both cases, there is little difference in the point of bifurcation between the two oligarchs. But when the price adjustment speed of imported soybeans from the United States is fixed and the price adjustment speed of imported soybeans from Brazil is gradually changing, the bifurcation range of equilibrium price of imported soybeans from the US increases and the range of chaotic price enlarges. Similarly, when the price adjustment speed of Brazilian soybean imports is fixed and the price adjustment speed of American soybean imports gradually changes, the equilibrium price bifurcation of Brazil soybean imports increases and the range of chaotic price enlarges. It can be seen that when one oligarch country's price adjustment speed is fixed and the other party's price adjustment speed is changed, the price of the fixed party will fluctuate greatly, while the changing party will be less affected.

4.2. Time Series Evolution Analysis of Price. The time series of game price reflects the change of equilibrium price over time. When $g_{1}=0.03$ and $g_{2}=0.03$, the system is in a stable state, at which time the stable Nash equilibrium price evolves over time as shown in Figure 4.

At this point, the evolutionary orbit of $\left(p_{1}, p_{2}\right)$ converges to a fixed point, which is the Nash equilibrium price obtained previously, as shown in Figure 5. 


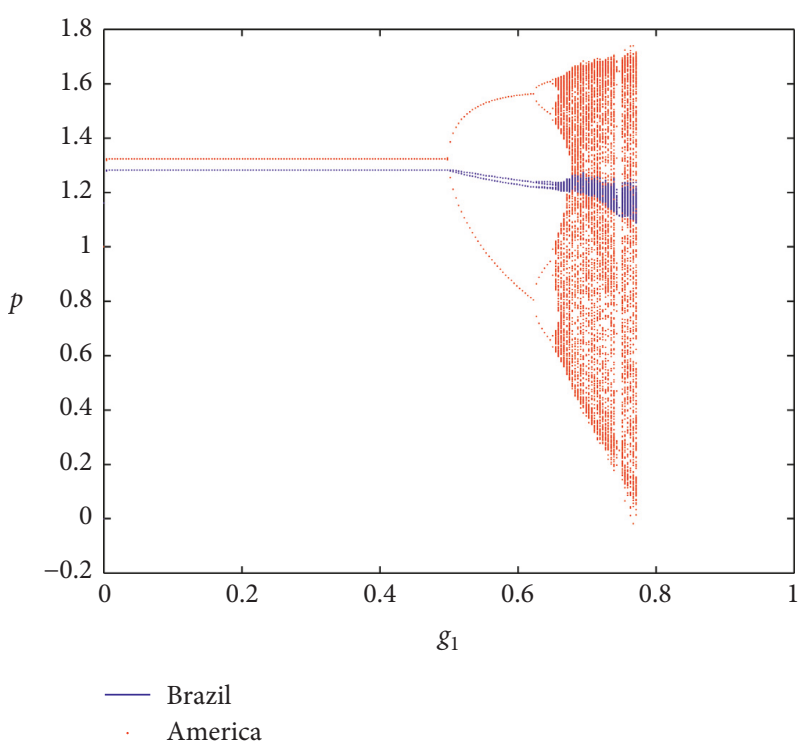

Figure 1: The trajectories of $p_{1}$ and $p_{2}$ diagram.

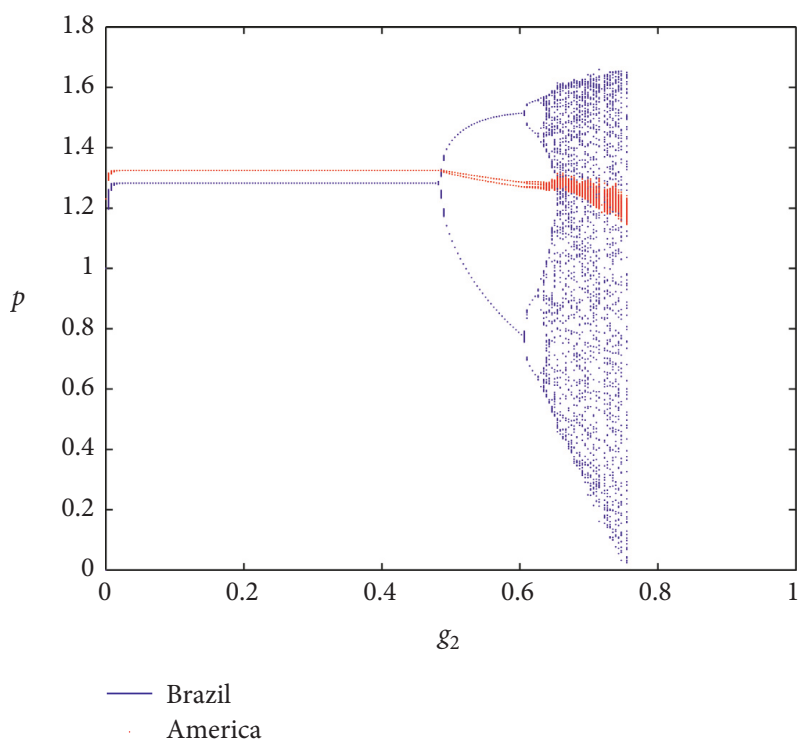

FIgURE 2: The tracks of $p_{1}$ and $p_{2}$ diagram.

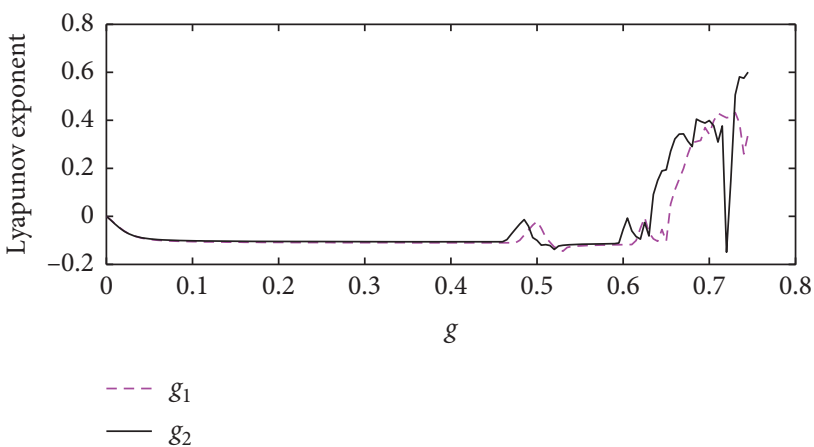

Figure 3: The maximum Lyapunov exponents with $p_{1}$ and $p_{2}$ diagram.

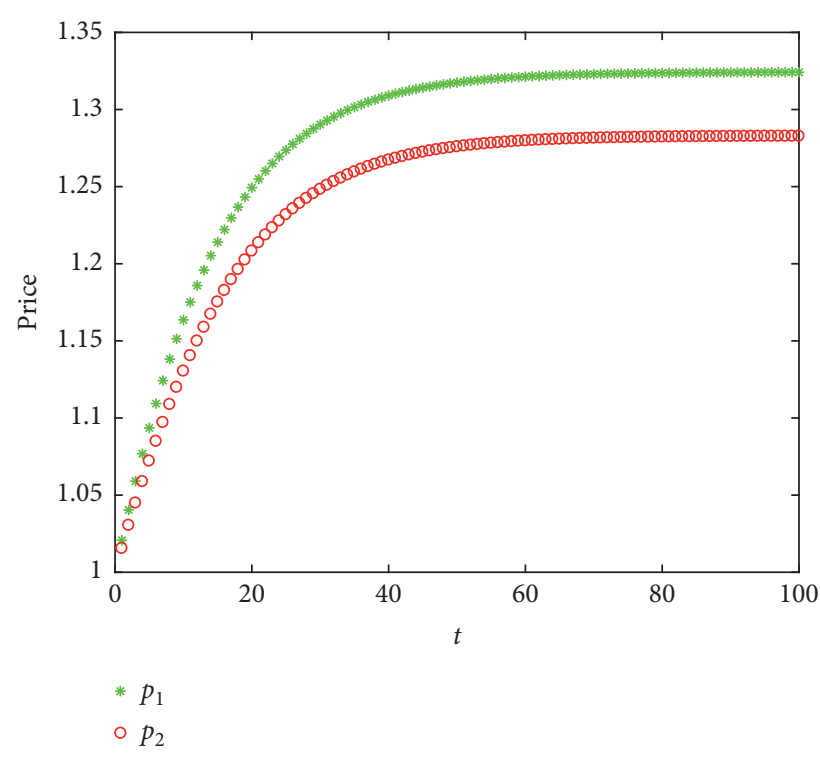

Figure 4: The stable Nash equilibrium price evolves over time diagram.

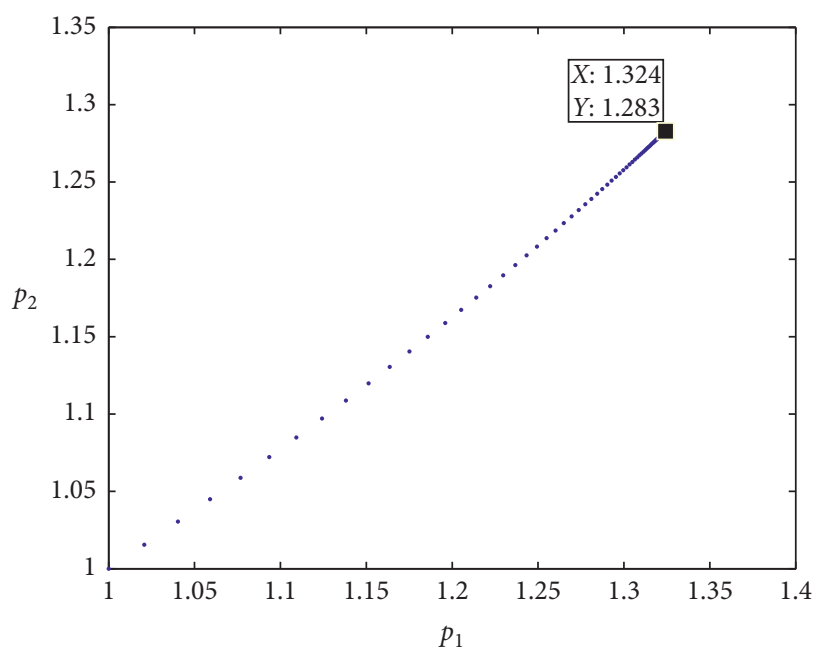

FIgURE 5: The Nash equilibrium price $p_{1}$ and $p_{2}$ diagram.

From the time point of data collected, it is found that after China imposed tariffs on US soybeans, the price of US imported soybeans increased significantly in a short period of time, while the price of Brazilian imported soybeans changed slightly. According to (27), $g_{1}=0.03$ and $g_{2}=0.54$. The maximum Lyapunov index changes from less than 0 to equal 0 and then to less than 0 . The system goes from stable state to bifurcation state. Time series graphs of game price $p_{i}(i=1,2)$ under the current price adjustment speed are drawn in Figure 6.

At this time, there are two price trends in both countries. At this point, the evolution trajectory of the bounded rational duopoly game is shown in Figure 7. The change trajectories finally converge to two points $(1.294,1.486)$ and $(1.306,0.9361)$. It is confirmed that the system of Figure 2 has entered the double bifurcation state. 


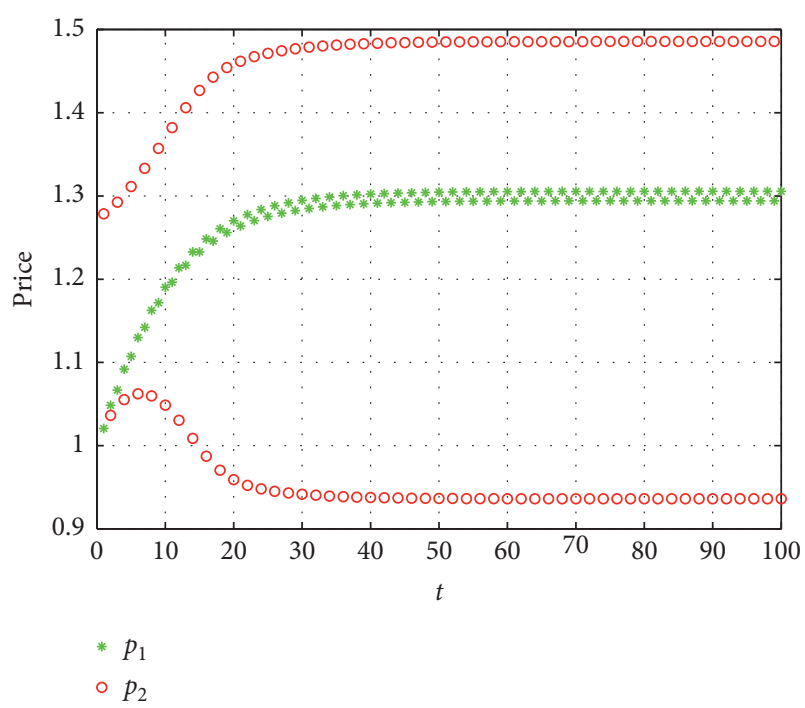

Figure 6: The current price adjustment speed diagram.

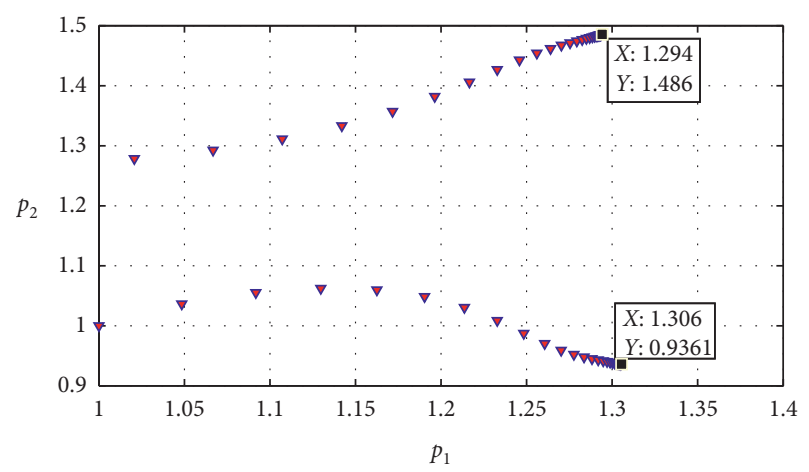

FIgURE 7: Time series graph of game prices with $g_{1}=0.03$ and $g_{2}=0.54$.

From the analysis in this section, when the price adjustment speeds of both players are controlled at a low level, the equilibrium price will remain stable in the region over time without interference from other external factors. If the speed of price adjustment is accelerated and beyond the stable region, the price of imported soybean will fluctuate greatly with the cycle, and the equilibrium price will change accordingly. Before the trade friction, the tariff preferential policy was implemented, and the change of soybean import price in the two oligarchs tended to be smooth. The emergence of tariff increases has led to rapid price changes, accelerated price adjustment, and consequently changed equilibrium prices, which confirms the above conclusions.

\section{Conclusion and Discussion}

Based on the classical game model, this paper constructs the bounded rational duopoly game models of the United States and Brazil. The demand elasticity is solved by Rotterdam model, and the elastic parameters in the game model are obtained. Then the elastic parameters are put into the model, the theorems are obtained and verified, and the corresponding economic analysis and policy recommendations are made. Through the simulation, we made some intuitive explanations about the meaning of economics. In this section, the model is used to predict the future soybean price.

5.1. Price Forecast. The above analysis shows that the price adjustment speed is an important parameter in the model (8). Estimating the price adjustment speed from the statistical data can predict the future soybean price.

From Figure 7 , we can see that the equilibrium price tends to two points after the price adjustment speed changes, $\left(p_{1}, p_{2}\right)=(1.294,1.486)$ and $(1.306,0.9361)$. In reality, the price of imported soybeans in the United States has risen. Obviously $\left(p_{1}, p_{2}\right)=(1.306,0.9361)$ is not in line with the actual situation. So we only discuss the case that $\left(p_{1}, p_{2}\right)=(1.294,1.486)$.

At the point $(1.294,1.486)$, the price of imported soybeans from Brazil dropped slightly by $2.26 \%$, while the price of imported soybeans from the United States rose by $15.82 \%$. Before the trade friction, China imposed tariff preferential policies on Brazil and the United States, and only 3\% tariff was levied on imported soybeans. As the two oligarchs in China's soybean import market, Brazil and the United States have constantly adjusted their price strategies to maximize profits, but the fluctuation of prices has slowed down. From the end of 2017 to the beginning of 2018, the average customs value of imported soybeans in Brazil and the United States remained $3.4 y u a n / \mathrm{kg}$ and $3.2 y u a n / \mathrm{kg}$, respectively. Referring to Wind Financial Terminal data, through (26) data statistics, it is concluded that the price adjustment speed in this stage is $g_{1}=0.03$ and $g_{2}=0.03$. They are brought into the model (8) and the equilibrium prices of the model are 2.648 yuan $/ \mathrm{kg}$ and 2.566 yuan $/ \mathrm{kg}$ (dimensional conversion has been overdone), respectively. Both prices are slightly lower than the real price.

The China-US trade friction broke out in April 2018. As of June 2018, the customs value of imported soybeans from the United States rose rapidly to an average of 13.72 yuan per kilogram in a short period of time, while that of imported soybeans from Brazil dropped to an average of 3.28 yuan per kilogram. Referring to the detailed data statistics, we can get the price adjustment speed $g_{1}=0.03$ and $g_{2}=0.54$ at this time. In model (8), the equilibrium prices of Brazil and the United States are 2.588 yuan $/ \mathrm{kg}$ and 2.972 yuan $/ \mathrm{kg}$, respectively, which are still slightly lower than the real prices. The price prediction errors are shown in Table 4.

In addition, our model has good prediction accuracy for price fluctuations. In reality, Brazil's soybean import price decreased by $3.5 \%$ while the US soybean import price increased by $16.25 \%$. In our model (8), the import price of Brazil decreased by $2.26 \%$. The import price of the United States increased by $15.82 \%$. The relative errors of model are $35.98 \%$ and $2.65 \%$, respectively. The prediction for price fluctuations is shown in Table 5 .

5.2. Evaluation of the Model. In the actual import trade, the change of soybean imports from Brazil and the United States to any extent can be quantified by (26) the price adjustment speed value and then brought into the model (8) to obtain 
TABle 4: Price prediction errors.

\begin{tabular}{lcccccc}
\hline$g_{i}$ & \multicolumn{3}{c}{$g_{1}=0.03, g_{2}=0.03$} & \multicolumn{3}{c}{$g_{1}=0.03, g_{2}=0.54$} \\
$p_{i}$ & Model & Real & Relative error (\%) & Model & Real & Relative error (\%) \\
\hline Brazil & 1.324 & 1.7 & 22.4 & 1.294 & 1.64 & 21.1 \\
America & 1.283 & 1.6 & 20 & 1.486 & 1.86 & 20.11 \\
\hline
\end{tabular}

Table 5: Prediction for price fluctuations.

\begin{tabular}{lccc}
\hline$p_{i}$ & Model (\%) & Real (\%) & Relative errors (\%) \\
\hline Brazil & -2.26 & -3.53 & 35.98 \\
America & 15.82 & 16.25 & 2.65 \\
\hline
\end{tabular}

the game equilibrium price under this situation. From the above analysis, we can see that the price obtained by the model is about $20 \%$ lower than the real price, and the price before and after the model is very close to the real price before and after the rise and fall; the difference of the US price is less than $3 \%$. It can be seen that the model used to simulate and predict the rise and fall of imported soybean prices in Brazil and the United States in a short period of time is ideal. When prices fluctuate dramatically, we can get a more accurate range of price changes.

There may be two reasons for the underestimation of the price predicted by the model. On the one hand, this paper only collects and uses the annual data from 2006 to 2017. The sample size is small, which results in the deviation of economic parameter estimation, and then affects the prediction of equilibrium price in the game model. On the other hand, the import cost will fluctuate due to RMB exchange rate, sea freight, weather, and other factors. In the future, the transportation mode of the two countries may be improved, and the cost will also change. Next, we can refer to the relevant import literature, establish cost function, and systematically consider the factors affecting the cost. According to the latest data, after the trade friction, Brazil and the United States fluctuated smoothly on the basis of fluctuating prices, further concretizing the model, and bringing the latest large-scale sample data into the Rotterdam model to obtain more economic parameters in line with the present stage and in the future. It can not only predict the increase of imported soybean price before and after the trade friction but also make the model more accurate in predicting the imported soybean price in the short time after the trade friction.

China imposed a $25 \%$ tariff on soybeans from the United States, which caused the import price of soybeans to rise rapidly in a short period of time. The import price of soybeans from the United States increased substantially but had little impact on the import price of soybeans from Brazil. This conclusion is the same as that obtained in Section 4.1. If soybean importers want to maintain stable market demand, they should take price reduction actions to maintain volatile import demand and avoid large losses. Otherwise, China will turn its demand for US soybeans to other countries.

The reason why the duopoly game model of Brazil and the United States was used before and after the trade friction is that after the outbreak of the trade friction, because of the soybean growth cycle and the past soybean planting inertia of other countries, as well as the impact of natural disasters in some countries this year, other countries cannot quickly meet the huge demand of soybean import in China in the short term of six months to one year. In order to maintain domestic supply stability, the United States is still a major oligopolistic supplier except Brazil in the short term, and the duopoly game model is still applicable to the United States and Brazil in the short term.

5.3. Requirement Analysis. In demand forecasting, the equilibrium prices corresponding to $g_{1}=0.03$ and $g_{2}=0.03$ are $p_{1}=1.324$ and $p_{2}=1.283$, and the equilibrium prices corresponding to $g_{1}=0.03$ and $g_{2}=0.54$ are $p_{1}=1.294$ and $p_{2}=1.486$. The equilibrium price under the above two conditions and the economic parameter values $a_{1}=2.3, a_{2}=$ $2.1, b_{1}=1.5, b_{2}=1.6, c_{1}=1$, and $c_{2}=1.2$ obtained by Rotterdam model above are brought into the demand function (1). The comparative analysis shows that the demand for imported Brazilian soybeans increases by $15.53 \%$, while the demand for imported American soybeans decreases by $22.05 \%$. This means that China-US trade frictions have led to a decrease in China's demand for imported soybeans from the United States and an increase in Brazil's demand for imported soybeans. According to the daily import data of soybean collected by Wind Financial Terminal, since January 2018 , there are a lot of incomplete data, which cannot get the precise change range of import volume. However, we can roughly compare the increase and decrease of soybean imports in the postwar period of 2018 with the same period in previous years. The demand for imported Brazilian soybeans increased compared with the same period in previous years, and the demand for imported American soybeans decreased significantly compared with the same period in previous years, which is consistent with the predicted trend of the demand model in this paper.

Demand will affect prices to a certain extent. In the current state of high tension in Sino-US trade relations, a substantial reduction in the import of US soybeans in the short term will help China to take the initiative in the late China-US trade negotiations. However, China has a large demand for soybeans. In the short run, the demand for soybeans from the United States will be transferred to other countries, which will theoretically lead to the rise of imported soybean prices from other countries. In Section 5.1, the price change of Brazilian imported soybeans predicted by the model is consistent with the actual trend of Brazilian imported soybean price change, showing a downward trend. The difference may be due to the decrease of China's demand for imported soybeans from the United States, which to a certain extent leads to competition among soybean 
producers other than the United States. South America, Southeast Asia, and other countries have lowered prices in order to obtain opportunities to export to China.

5.4. Suggestions. From a long-term point of view, without affecting domestic consumption demand and industrial development, we need to take certain measures to reduce the import scale substantially. As far as China is concerned, there is great potential for soybean cultivation in China. China should speed up the structural reform of agricultural supply side, properly increase the subsidy for soybean cultivation, encourage soybean cultivation, increase $R \& D$ investment, improve the quality and quantity of domestic soybean, reduce the dependence on imported soybean, and increase domestic soybean supply. As far as China's foreign strategy is concerned, the economic and trade frictions between China and the United States continue to increase China's imports of soybeans to South America and the "along the way" countries and further reduce the dependence on us soybeans. Since July 1, China has reduced the tariff rates on soybean imports from 3\% to zero in India, Korea, Bangladesh, Laos, and Sri Lanka. Through the tariff reduction and exemption policy, developing and tapping the soybean planting potential of other countries in the world, increasing investment in soybean planting abroad, improving the enthusiasm of soybean planting in other countries, realizing diversification of import market, and optimizing import choice are very important for filling the vacancy of imported soybean in the United States and maintaining the stability of soybean market in China.

\section{Data Availability}

The data used to support the findings of this study are available from the corresponding author upon request. The questionnaire data were acquired mainly through e-mail and paper filling out.

\section{Conflicts of Interest}

The authors declare no conflicts of interest.

\section{Authors' Contributions}

Yi Wang selected the topic and Hui Wang drafted the manuscript. All the authors edited the paper. All authors have read and approved the final manuscript.

\section{Acknowledgments}

This work was supported by the National Natural Science Foundation of China (no. 11601270). This work was also supported by the Philosophy and Social Science Program of Jinan (no. JNSK18B17).

\section{References}

[1] H. N. Agiza, A. S. Hegazi, and A. A. Elsadany, "The dynamics of Bowley's model with bounded rationality," Chaos, Solitons \& Fractals, vol. 12, no. 9, pp. 1705-1717, 2001.
[2] H. N. Agiza and A. A. Elsadany, "Nonlinear dynamics in the Cournot duopoly game with heterogeneous players," Physica A: Statistical Mechanics and Its Applications, vol. 320, no. 1, pp. 512-524, 2003.

[3] H. N. Agiza and A. A. Elsadany, "Chaotic dynamics in nonlinear duopoly game with heterogeneous players," Applied Mathematics and Computation, vol. 149, no. 3, pp. 843-860, 2004.

[4] A. A. Elsadany, "Dynamics of a delayed duopoly game with bounded rationality," Mathematical and Computer Modelling, vol. 52, no. 9-10, pp. 1479-1489, 2010.

[5] G.-I. Bischi and F. Lamantia, "Nonlinear duopoly games with positive cost externalities due to spillover effects," Chaos, Solitons \& Fractals, vol. 13, no. 4, pp. 701-721, 2002.

[6] F. Tramontana, "Heterogeneous duopoly with isoelastic demand function," Economic Modelling, vol. 27, no. 1, pp. 350-357, 2010.

[7] A. Bonatti, G. Cisternas, and J. Toikka, "Dynamic oligopoly with incomplete information," The Review of Economic Studies, vol. 84, no. 2, pp. 503-546, 2016.

[8] A. Nagurney and T. Wolf, "A Cournot-Nash-Bertrand game theory model of a service-oriented Internet with price and quality competition among network transport providers," Computational Management Science, vol. 11, no. 4, pp. 475502, 2014.

[9] A. E. Matouk, A. A. Elsadany, and B. Xin, "Neimark-Sacker bifurcation analysis and complex nonlinear dynamics in a heterogeneous quadropoly game with an isoelastic demand function," Nonlinear Dynamics, vol. 89, no. 4, pp. 2533-2552, 2017.

[10] X. Wang, Y. Xie, H. S. Jagpal, and S. Yeniyurt, "Coordinating $\mathrm{R} \& \mathrm{D}$, product positioning, and pricing strategy: a duopoly model," Customer Needs and Solutions, vol. 3, no. 2, pp. 104-114, 2016.

[11] P.-y. Nie, "Comparing horizontal mergers under Cournot with bertrand competitions," Australian Economic Papers, vol. 57, no. 1, pp. 55-80, 2018.

[12] I. Saglam, "Ranking supply function and Cournot equilibria in a differentiated product duopoly with demand uncertainty," Games, vol. 9, no. 3, p. 60, 2018.

[13] H. N. Agiza, A. S. Hegazi, and A. A. Elsadany, "Complex dynamics and synchronization of a duopoly game with bounded rationality," Mathematics and Computers in Simulation, vol. 58, no. 2, pp. 133-146, 2002.

[14] H. Wang and J. Ma, "Complexity analysis of a CournotBertrand duopoly game with different expectations," Nonlinear Dynamics, vol. 78, no. 4, pp. 2759-2768, 2014.

[15] Z. Guo and J. Ma, "Dynamics and implications on a cooperative advertising model in the supply chain," Communications in Nonlinear Science and Numerical Simulation, vol. 64, pp. 198-212, 2018.

[16] J. Ma and H. Wang, "Complexity analysis of dynamic noncooperative game models for closed-loop supply chain with product recovery," Applied Mathematical Modelling, vol. 38, no. 12, pp. 5562-5572, 2014.

[17] J. Ma and L. Xie, "The comparison and complex analysis on dual-channel supply chain under different channel power structures and uncertain demand," Nonlinear Dynamics, vol. 83, no. 3, pp. 1379-1393, 2016.

[18] J. Zhang and J. Chen, "Externality of contracts on supply chains with two suppliers and a common retailer," Journal of Industrial and Management Optimization, vol. 6, no. 4, pp. 795-810, 2010.

[19] J. Ma and L. Sun, "Complexity analysis about nonlinear mixed oligopolies game based on production cooperation," IEEE 
Transactions on Control Systems Technology, vol. 26, no. 4, pp. 1532-1539, 2018.

[20] J. Ma and H. Ren, "Influence of government regulation on the stability of dual-channel recycling model based on customer expectation," Nonlinear Dynamics, vol. 94, no. 3, pp. 17751790, 2018.

[21] D. Li and A. Nagurney, "Supply chain performance assessment and supplier and component importance identification in a general competitive multitiered supply chain network model," Journal of Global Optimization, vol. 67, no. 1-2, pp. 223-250, 2017.

[22] J. Li, C. Zhang, Q. Sun, Z. Chen, and J. Zhang, "Changing the intensity of interaction based on individual behavior in the iterated prisoner's dilemma game," IEEE Transactions on Evolutionary Computation, vol. 21, no. 4, pp. 506-517, 2017.

[23] J. Zhang and Z. Chen, "Contact-based model for strategy updating and evolution of cooperation," Physica D: Nonlinear Phenomena, vol. 323-324, pp. 27-34, 2016.

[24] J. Zhang, Z. Xu, and Z. Chen, "Effects of strategy switching and network topology on decision-making in multi-agent systems," International Journal of Systems Science, vol. 49, no. 9, pp. 1934-1949, 2018.

[25] J. Zhang, Y. Zhu, Q. Li, and Z. Chen, "Promoting cooperation by setting a ceiling payoff for defectors under three-strategy public good games," International Journal of Systems Science, vol. 49, no. 10, pp. 2267-2286, 2018.

[26] J. Ma and Z. Guo, "The parameter basin and complex of dynamic game with estimation and two-stage consideration," Applied Mathematics and Computation, vol. 248, pp. 131-142, 2014.

[27] J. Ma and F. Wu, "The application and complexity analysis about a high-dimension discrete dynamical system based on heterogeneous triopoly game with multi-product," Nonlinear Dynamics, vol. 77, no. 3, pp. 781-792, 2014.

[28] J. Ma and H. Tu, "Analysis of the stability and Hopf bifurcation of money supply delay in complex macroeconomic models," Nonlinear Dynamics, vol. 76, no. 1, pp. 497-508, 2014.

[29] J. Ma, T. Xu, Y. Hong, and X. Zhan, "Impact research on a nonlinear cold chain evolutionary game under three various contracts," International Journal of Bifurcation and Chaos, vol. 29, no. 5, Article ID 1950058, 2019.

[30] L. Mu, P. Liu, Y. Li, and J. Zhang, "Complexity of a real estate game model with a nonlinear demand function," International Journal of Bifurcation and Chaos, vol. 21, no. 11, pp. 3171-3179, 2011.

[31] F. Liu and Y. Li, "Complex nonlinear dynamic system of oligopolies price game with heterogeneous players under noise," International Journal of Bifurcation and Chaos, vol. 26, no. 11, Article ID 1650183, 2016.

[32] Y. Wang, X. Su, and S. Guo, "The optimal confidence intervals for agricultural products' price forecasts based on hierarchical historical errors," Entropy, vol. 18, no. 12, p. 439, 2016.

[33] X. Su, H. Liu, and S. Hou, "The trilateral evolutionary game of agri-food quality in farmer-supermarket direct purchase: a simulation approach," Complexity, vol. 2018, no. 2, p. 11, 2018.

[34] X. Su, Y. Wang, S. Duan, and J. Ma, "Detecting chaos from agricultural product price time series," Entropy, vol. 16, no. 12, pp. 6415-6433, 2014.

[35] H. Theil, "The information approach to demand analysis," Econometrica, vol. 33, no. 1, pp. 67-87, 1965.

[36] J. M. Alston and J. A. Chalfant, "The silence of the lambdas: a test of the almost ideal and Rotterdam models," American
Journal of Agricultural Economics, vol. 75, no. 2, pp. 304-313, 1993.

[37] T. Puu, Attractors, Bifurcations, and Chaos: Nonlinear Phenomena in Economics, Springer-Verlag, Berlin, Germany, 2003.

[38] J.-h. Ma and Y.-s. Chen, "Study for the bifurcation topological structure and the global complicated character of a kind of nonlinear finance system(I)," Applied Mathematics and Mechanics, vol. 22, no. 11, pp. 1240-1251, 2001.

[39] J.-h. Ma and Y.-s. Chen, "Study for the bifurcation topological structure and the global complicated character of a kind of nonlinear finance system(II)," Applied Mathematics and Mechanics, vol. 22, no. 12, pp. 1375-1382, 2001. 


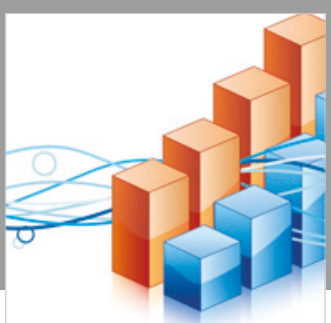

Advances in

Operations Research

\section{-n-m}
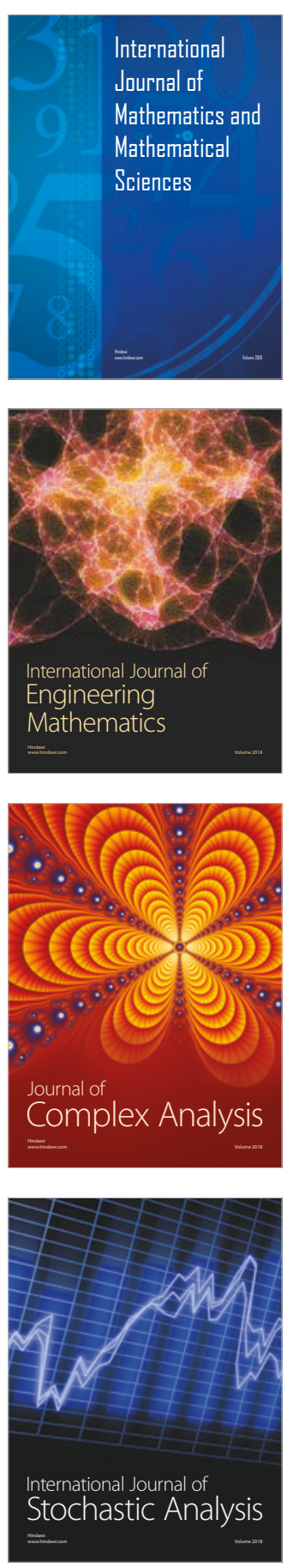
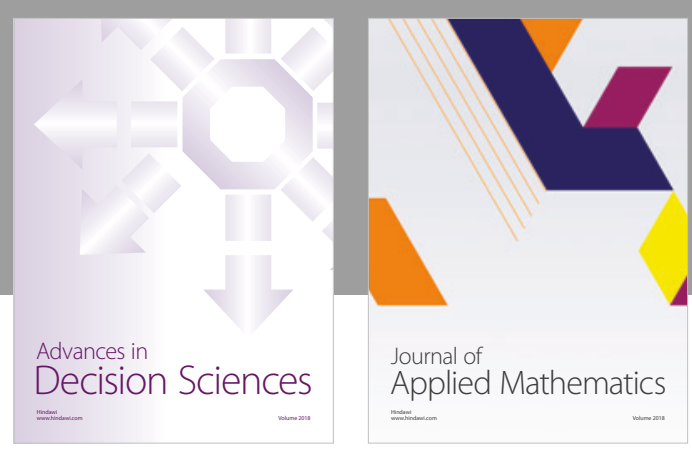

Journal of

Applied Mathematics
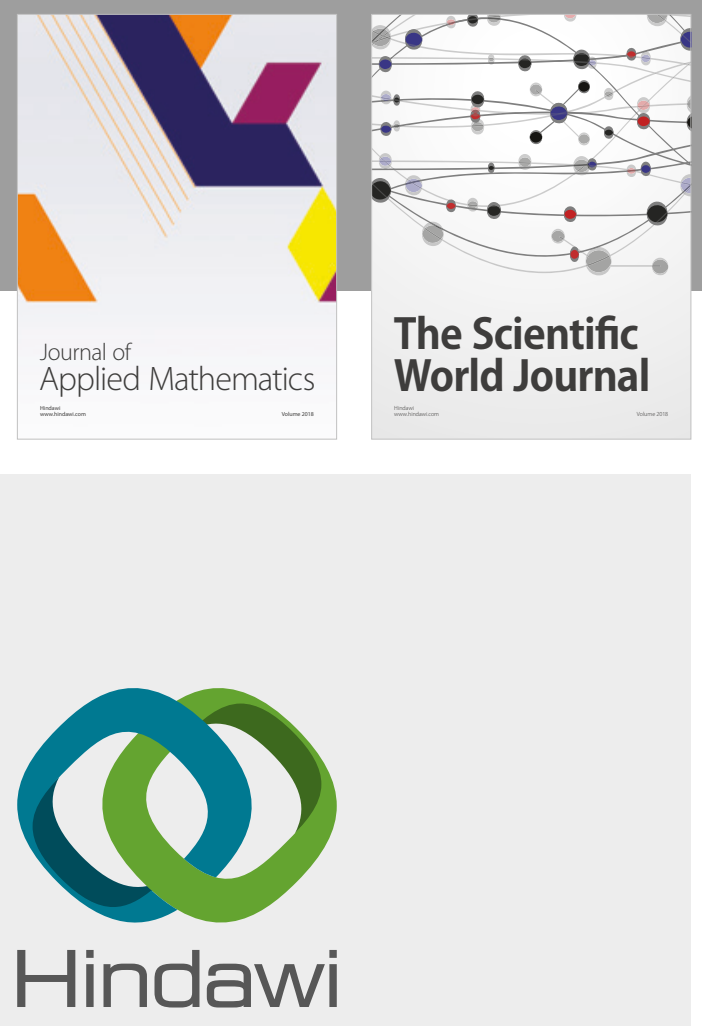

Submit your manuscripts at

www.hindawi.com

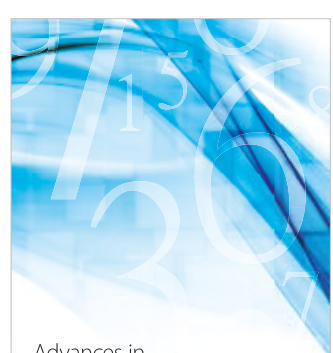

Advances in
Numerical Analysis
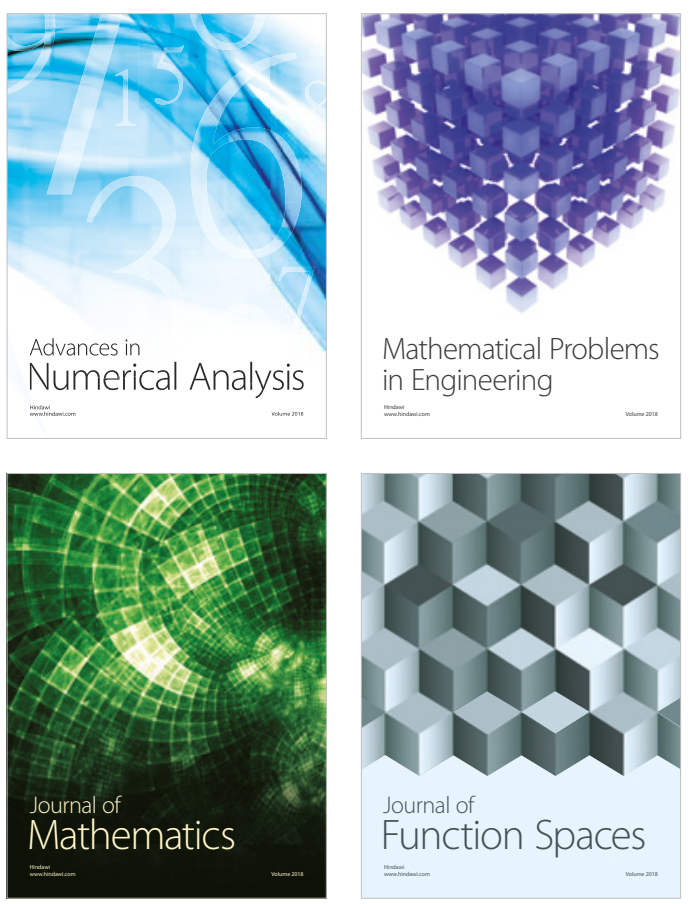

Mathematical Problems in Engineering

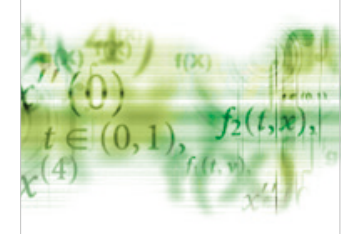

International Journal of

Differential Equations

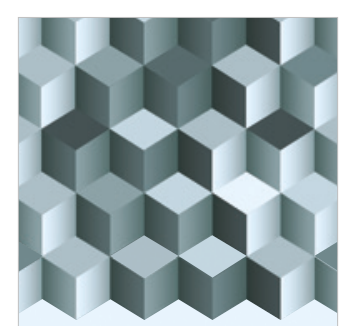

Journal of

Function Spaces
The Scientific

World Journal

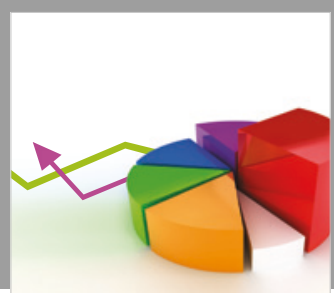

Journal of

Probability and Statistics
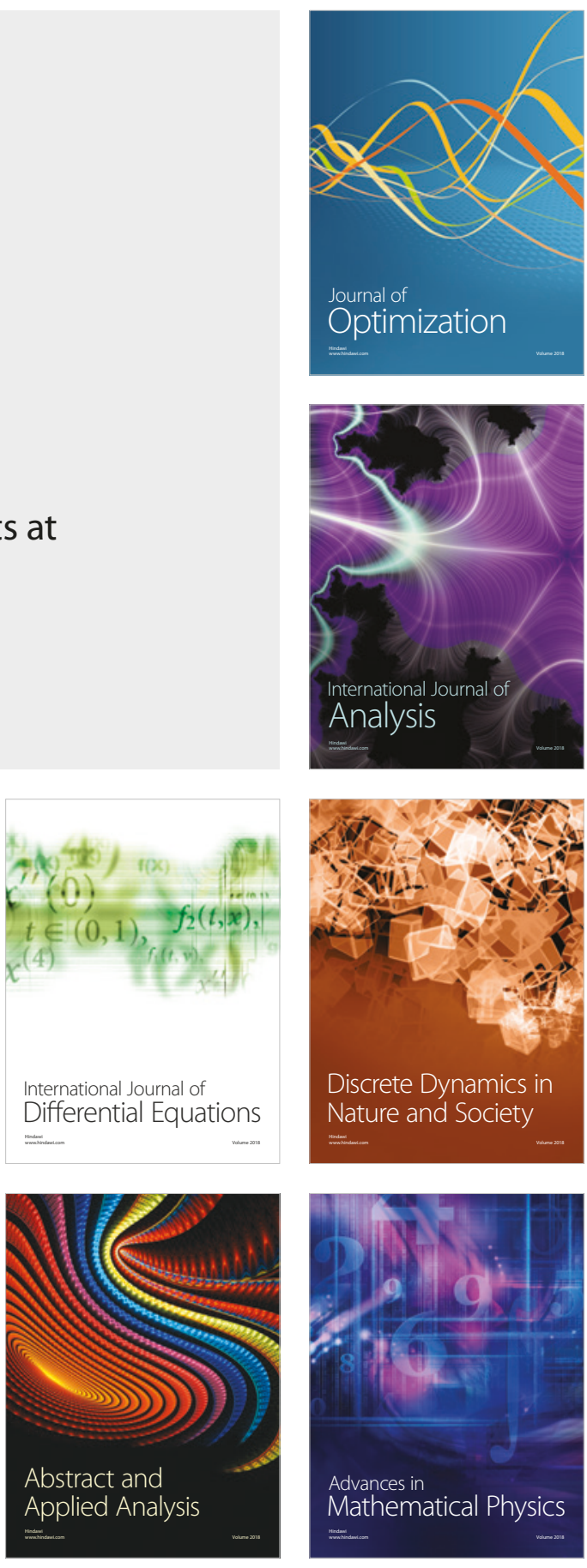